\title{
Peace Promotion through Hausa Proverbs: A Sociolinguistic Perspective
}

\author{
Maman Toukour LAWALI ${ }^{1 *}$, Ayodele Adebayo ALLAGBE ${ }^{2}$ \\ ${ }^{1,2}$ Département d'Anglais, Faculté des Lettres et Sciences Humaines (FLSH), Université de Zinder (UZ), \\ République du Niger, Unité de Recherche en Sciences Sociales, Humaines, et de l'Education (UR_2SHE). \\ *Corresponding Authors: Maman Toukour LAWALI, Département d'Anglais, Faculté des Lettres et \\ Sciences Humaines (FLSH), Université de Zinder (UZ), République du Niger, Unité de Recherche en \\ Sciences Sociales, Humaines, et de l'Education (UR_2SHE).
}

\begin{abstract}
This paper highlights the contribution of Hausa proverbs in promoting peace in social life. The study revolves around the translation, definition and analysis of five main Hausa proverbs, namely: zaman lafiya yafi zama dan sarki, hakuri maganin zaman duniya, tashin hankali yana kawo tsiya, maso fada wawa ne and rigakafi yafi magani. The idea is to prove the relevance of the use of these proverbs in the perspective of strengthening peaceful coexistence between communities. To demonstrate the impact of these proverbs in the dynamics of the pacification of social life, the article draws its theoretical underpinnings from sociolinguistics. The analysis reveals the striking dimensions of the Hausa philosophy from the perspective of peace management and conflict prevention.
\end{abstract}

Keywords:peace promotion, proverb, conflict prevention, Hausa society.

\section{INTRODUCTION}

The world in general is being tormented by the yoke of conflicts and wars. The growing instability occurs diversely; from civil war, terrorism, to tribal or inter-ethnic conflicts. Thus, one may ask: Why are these conflicts permanent? Why is peace constantly disturbed? In a tentative answer, M. Shehu \& I.A. Muhammad (2019, p. 125) think that instability is intimately linked to man; thus, they submit that:

\begin{abstract}
Conflicts are found at every stage of life; individuals, groups, associations, clubs, societies, local, national as well as international communities experience conflict in one way or the other. That, however, includes religious, ethnic, political and communal among others. Conflicts are features of life.
\end{abstract}

The above quote shows that conflicts are permanent in every corner of the globe. That means stability and harmony are highly needed in society. Thus, decision makers, international institutions like the United Nations, NGOs, scholars, etc., should actively engage in conflict resolution and the search for peace and stability through several and various means such as education, mediation, dialogue, and sensitizing people on the importance of peace among them. According to I. Okpewho (1983, p. 23), "the survival of a society is a result of adequate conflict resolution and that unitive customs arise from the fear of social disintegration." But what does peace mean? M. Shehu \& I.A. Muhammad (2019, p. 125) define peace as:

One of the highest values in every community. Its meaning is multilateral and multi-disciplinary, depending on which notion is central in the determination of "peace" as a concept. The most common use of peace is in the absence of dissention, violence or war. Peace is also seen as a state of mind in concourse with serenity: a state of harmony, tranquillity, concord and balance of equilibrium of powers. Peace is the opposite of conflict; it abhors violence and war.

Besides, this quotation brings out the importance of peace in society; and shows that peace has a large scope of meaning and covers man's entire life. That is why no development is possible without it. Hausa people have earlier understood this fact; they use certain proverbs as a means to maintain peace and stability among themselves. They believe that proverbs, or Karin Magana in the Hausa language, constitute an efficient mechanism of promoting peace in society. In the similar vein, A. Zeinab \& A. Halima (2015, p. 27) claim that "Proverbs are employed in different kinds of situation in [the] Hausa society to control several activities without the use of force or harsh language." 
This study focuses on the extent to which proverbs help to promote peace in theHausa society and beyond. Methodologically, this paper purposively selects five Hausa peace-promoting proverbs, namely: zaman lafiya yafi zama dan sarki, hakuri maganin zaman duniya, tashin hankali yana kawo tsiya, maso fada wawa ne and rigakafi yafi magani. These proverbs are translated into English by means of literal and equivalence methods before they are analysed from a sociolinguistic perspective.

\section{LiteratURE REVIEW AND THEORETICAL FRAMEWORK}

Proverbs, one of the main forms of oral literature, have been recently explored to show how they function in society, how they relate to society, how they encode its cultural values, mores, value systems, beliefs, etc. As far as Hausa proverbs are concerned, many research works have been carried out by African and non-African scholars. Among them Merrick (1905), Kirk-Greene (1966), Madauchi et al (1980), and Tudunwada (2006) can be cited, their works remain the basis of Hausa proverb collections. These writers are actually credited for having gathered most of the currently used Hausa proverbs and translated them into English. In this perspective, their works serve as a data bank of Hausa written proverbs.

Moreover, scholars like Ibrahim (1985), Bichi (1995), Kabir (2005), Hassan (2009) Zainab and Halima (2015), who vehemently posit that proverbs are employed in various situations in the Hausa society, have collected and shown the prominent functions of proverbs in terms of education and discipline. Furthermore, Shehu and Muhammad (2019) have proven that Hausa proverbs are suitable means for resolving conflicts and very efficient for promoting peace in the Hausa society. The current study examines the same issue with a special emphasis on the use of language in context. It draws its theoretical insights from sociolinguistics. Sociolinguistics is the science which studies "[...] the relationship between language and society, or of the various functions of language in society [...]" (R. Wardhaugh, 2006, p. 1). According to P. Trudgill (2000, p. 1), language generally plays two major functions: 1. It serves as a means of communicating information about a given topic or subject-matter. 2. It is a means of establishing and maintaining relationships with other people. Underlying sociolinguistics is the view that language is a social phenomenon and that it is closely tied up with the social structure and value systems of society.

Proverbs, for instance, are an important verbal art genre, whose study can reveal the link between language and society. In other words, proverbs are language features whose analysis can provide a full insight into the culture or social structure of the speech community in which they are used. W. Mieder (2004, p. 3) defines a proverb as "A short, generally known sentence of the folk which contains wisdom, truth, morals, and traditional views in a metaphorical, fixed and memorisable form and which is handed down from generation to generation." The preceding definition clearly shows that proverbs play an important role in the life of a society. Concurring with the fore going, R. D. Abrahams (1973, p. 117) argues that a:

Proverb is a short and witty traditional expression that arises as part of everyday discourse as well as in the more highly structured situations of education and judicial proceedings. Each proverb is a full statement of an approach to a recurrent problem. It presents a point of view and a strategy that is self-sufficient, needing nothing more than an event of communication to bring it into play.

In the above quote, one can easily understand that proverbs are deeply rooted in the social life of a speech community, the social life of the Hausa speech community, for example. Proverbs are always used to settle a given preoccupation among people. They constitute a suitable channel through which values are transmitted in the community, from one generation to another. In this sense, Bland (1914) (quoted in M. Shehu \& I.A. Muhammad, 2019, p. 126) contends that a proverb is "a short figurative expression or sentence currently used, commending or reproving the person or thing to whom or which it is applied, and often containing some moral precepts or rule for our conduct of life." It is obvious in the foregoing that proverbs are used to moralise individuals and educate them to behave correctly in favour of peace and harmony in society.

A proverb is called Karin Magana in Hausa. According to A. Zeinab \& A. Halima (2015, p. 27), "The Hausa proverb is said to be the oldest and the most important genre of folklore which is used by people in many contexts. Hausa proverbs give answers to recurrent problems; these proverbs are also used to revive history, to develop language, to entertain and to educate." This shows that proverbs are the mostly used form of oral literature in the Hausa society. Further, A. Zeinab \& A. Halima (2015, p. 27) add that: 
Proverbs as a form of oral literature are the most consistent and most employed by the Hausa people than folktale, songs, chants, myth, etc. They are frequently used in every situation. Hausa people as a society have their own culture which is strictly followed according to its doctrines that are strongly rooted in morality. In [the] Hausa society, proverbs express morals and ethics of people. Hausa proverbs maintain conformity to cultural values and accepted pattern of behaviour.

There fore mentioned quote actually highlights the precious place of proverbs in the Hausa society and their moralistic and educational functions. They are an important part of Hausa people's culture, for they concern almost every aspect of their social life. That is why individuals, old or young, use them regularly in their interactions. Hausa People use proverbs to convey immense values like peace, harmony and stability in society. It is in this sense that R. Finnegan (1970, p. 390) posits that "Karin Magana can be seen to have an immense value to speakers and orators." Moreover, M. Shehu \& I.A. Muhammad (2019, p. 126) observe that:

The role of Hausa proverbs in the life of the Hausas can never be over-emphasized. Besides leisure, they give courage, determination and define a better way of life. It touches almost all aspects of life which includes culture, religion, politics, socialization, knowledge, economics, love for one another as well as peace and conflict resolution to mention but a few.

In the Hausa society, proverbs are considered as a school through which people learn much about their ancestral values and the better living conditions among them. For instance, the promotion of peace and harmony in society constitutes an essential aspect of this learning. This means that Hausa people maintain peace and harmony through certain proverbs dedicated to the same cause. Let us now examine some of these proverbs to see how they contribute to the promotion of peace in the Hausa society.

\section{Analysis of The Selected Hausa Proverbs}

To prevent conflicts and promote peaceful coexistence, Hausa people use proverbs (Karin Magana). In this perspective, M. Shehu \& I.A. Muhammad (2019, p. 126) observe that "There are quite numbers of Hausa proverbs that are thematically built to promote peace and conflict resolutions. Such proverbs either discourage conflicts or encourage peaceful coexistence." Furthermore, M. A. Mode $(2015$, p. 56) states that "Hausa proverbs have enormous potentiality for conflict prevention and conflict resolution." Among those proverbs, we select five, as mentioned earlier on, that thematically convey the message of peace and conflict prevention in society. These proverbs are analysed thematically and stylistically to discover their contribution to peace preservation and conflict resolution. The first proverb is the following:

\section{Zaman lafiya yafi zama dan sarki}

To be in peace is better than to be a prince (literal translation)

Peace is priceless (equivalent translation)

This proverb represents the eminent formula of proverbs dealing with a peace message in the Hausa society. This is because, not only does it directly express the value of peace, but it also states clearly the expected objective of its use. Therefore, the proverb zaman lafiya yafi zama dan sarki (to be in peace is better than to be a prince) is a founding proverb upon which any other formula can be posed to promote peace and encourage peaceful coexistence among people in the Hausa society and beyond. Thematically, this proverb expresses the importance of peace in society. Stylistically, it shows the superiority of peace over all, even the throne or the son of the king (prince) who is a future king, is not to be compared with the value of peace in society. The use of comparison between two important things in any society, namely: zaman lafiya (being in peace) and zama dan sarki (being a prince) in the proverb accounts for the special attention people have for peace in the Hausa society.

The proverb zaman lafiya yafi zama dan sarki also reveals the Hausa people's love of peace and its preservation. That is why M. Shehu \& I.A. Muhammad (2019, p. 126) admit that "The proverb here is a testimony of Hausa love of peace. To them, peace has the greatest value, even greater than being a prince or a king." This further shows the level of determination and sacrifice of Hausa people for the sake of peace and peaceful coexistence; they can sacrifice everything they possess, even a notorious position to preserve peace in their community. In this sense, M. A. Mode (2015, p. 57) points out that 
"Despite this unique position, the occupant of the throne is ready to sacrifice his pleasure and desires in the interest of peace."

Moreover, the way the proverb is formed realises a manifest will of promoting peace. Firstly, morphologically, it is composed of mono-morphemic and very common words like zaman, lafiya, sarki which everybody, including children, can easily articulate. Besides, there is a significant pedagogy encoded in the formation of this proverb which shows the need of peaceful living among people. Secondly, the proverb is very explicit semantically. This really makes its meaning accessible to both the user and the audience. In fact, this proverb constitutes a suitable answer to the world's endless conflicts and wars in that it exhorts people to see the value of peace which is the sine qua non condition to a sustainable development. Again, this proverb is an address to the world in general to consider peaceful coexistence and harmony among people as something which has no equal. The second proverb is closely linked to the first one:

\section{Hakuri maganin zaman duniya}

\section{Patience is a Universal Remedy}

This proverb suggests a global option to peace management. It conveys, on the one hand, the sense of conflict prevention among people, and on the other hand, it serves as a panacea for conflict resolution. Hausa people permanently use this proverb to encourage peaceful coexistence in society. This is because the proverb is very simple and easily said to reconciliate two conflicting persons or groups, or to calm tension among people. Hakuri maganin zaman duniya (patience is a universal remedy) is formed by the association of two major concepts: hakuri (patience) and zaman duniya (life or the world). Hakuri is one of the most important human values that encourage man to get other qualities like tranquillity, serenity, tolerance, and satisfaction vis à vis his environment. Also, hakuri is a cardinal and golden value that when it is shared and lived, the society stays in peace. In the similar vein, M. Shehu \& I.A. Muhammad (2019, p. 128) note that "Patience is apparent, especially in a complex world where people have divergent differences; for instance, cultural, religious and tribal altercations become obvious that people must in one way or another preserve and exercise patience for at least togetherness sake."

The above-mentioned proverb truly fits with other Hausa proverbs which rely on hakuri (patience) to promote peace. Among these proverbs, we can mention mahakurci, mawadaci (the man with patience is successful). This proverb highlights the importance of patience in one's life by showing that a patient person is always successful in life. And the best success is that of peaceful coexistence in society. Another proverb promoting peace through patience is mai hakuri ke dafa dutsi hal yasha roman sa (only a patient person can cook a stone and drink even its juice); this proverb shows also that only patience results in success, but it requires endurance and tolerance. And the last proverb is wa dunia ta dama? sai maras hakuri (who finds the world troublesome? The impatient man). This proverb shows that with patience there will be no conflicts in the world.

Therefore, Hausa people believe that patience is one of the best suitable values that promote and preserve peace in society. That is why there are several Hausa proverbs which put a great emphasis on patience as the examples mentioned above. A. Zeinab \& A. Halima (2015, p. 29) really concur with the foregoing when they submit that "Patience is a major theme in Hausa proverb." This can be also seen through the example of young couples to whom patience is permanently recommended for a sustainable peaceful coexistence in their families. Hakuri, as a remedy, allows people to resolve misunderstanding and conflicts among them. Then, if the world in general observes the proverb hakuri maganin zaman duniya, there will be no conflicts, contrarily to what we unfortunately observe everywhere today. The third proverb encodes the attitudes of man which jeopardise peace in social life:

\section{Maso fada wawa ne}

\section{A quarrelsome person is a fool}

This proverb is one of the most currently used among the Hausa proverbs to discourage attitudes which encourage conflicts in society. Through this proverb, Hausa people think that whoever disturbs peace and brings instability among people is unhealthy. In this sense, M. A. Mode (2015, p. 56) maintains that "A quarrel loving person is described as a fool; i.e. someone who is childish and who cannot reason very well and do what is expected of him. The Hausa people believe that it is only those 
that don't know what they are doing that could encourage others to fight and cause trouble." This is not only because of the sacredness of peace, but also due to the negative consequences that disputes may provoke in the society. No wonder M. Shehu \& I.A. Muhammad (2019, p. 126) contend that "A quarrelsome person is described as a fool [in the Hausa society] [...] because such action brings disarray in the community. Nobody supports foolhardy. Therefore, all act[s] of violence are rendered null and void and could never be entertained."

Maso fada wawa ne is actually a very short proverb, composed of four mono-morphemic words, it concentrates its educational aim on conflict and its consequences. The different terms in the proverb are also very simple and semantically accessible to almost every Hausa ethnic group member. This makes it easier even for children to understand and use it in their daily life. The proverb is centered on two major terms: fada (quarrel or conflict) and wawa (fool or crazy). These terms are used to encourage people not to be quarrelsome and to banish quarrel in the community. The two terms also encourage individuals to behave well in society. That is why S. A. Sarbi (2019, p. 137) asserts that "Indeed, proverbs are capable of correcting behaviour lapses, admonishing, settling arguments and disputes, etc."Furthermore, this proverb aims to settle conflicts between two groups of people or/and to reconciliate them. In line with the foregoing, A. Zeinab \& A. Halima (2015, p. 29) admit that "Hausa proverbs are used in settling disputes among villages, towns, clans and even among brothers. The ability of the speaker to utili[s]e the appropriate proverbs that refer to the subject matter in question, gives peace a chance easily." Their use therefore fosters good understanding and mutual tolerance in society by showing that good persons are those who dislike conflicts for the sake of a peaceful coexistence among people.

In a nut shell, the proverb maso fada wawa ne reflects the Hausa people's sense of peace and harmony in their speech community and beyond. Indeed, children are educated on this way to be disciplined and respectful towards their parents and any other person in society. In this perspective Bichi (1995) (quoted in S. A. Sarbi (2019, p. 137) affirms that:

Children are habitually introduced to proverbs at an early impressionable age [...] and that proverbs play a significant part in shaping ways of life and perpetuating attitudes of mind [...] They are well worth studying because in addition to the usual homely truth, a good deal of popular philosophy can be traced in them.

The above quote plainly reveals the prominent role of proverbs in the Hausa society as they serve to encode its philosophy (peaceful coexistence and conflict banishment)and transmit it from one generation to another. This clearly shows the close link between language (the use of proverbs) and the social structure and value systems of the Hausa society. The fourth proverb highlights the impacts of conflicts.

\section{Tashin hankali yana kawo tsiya}

\section{Conflict Brings Poverty}

For the Hausa people, conflicts are the source of all evils and regression. They believe that where there is conflict, there will be no development. That is why M. Shehu \& I.A. Muhammad (2019, p. 126) affirm that "peace is directly related to economic prosperity. Only with a peaceful atmosphere would there be an economic growth. The belief is that, without a peaceful environment, there could not be sustainable economic development." Shehu \& Muhammad perceive the poverty mentioned through the proverb on the economic angle, that is why they mention that no economic development is possible with conflicts. Similarly, M. A. Mode (2015, p. 56) asserts that "conflict and economic prosperity are incompatible. This is to say, it is not possible to get economic prosperity as long as conflict prevails. It is [therefore] imperative that for the attainment of any economic growth and meaningful development, peaceful atmosphere must be created."

Indeed, the fourth proverb warns people about the prominence of peace to the sustainable development of a nation and draws people's attention to that fact, but it has a wider meaning. The poverty it evokes is a general one. The term tsiya in Hausa expresses a total poverty which designates instability and misery which cause lack of tranquillity and serenity in society. These characterise the outcomes of any conflict in society; when there is no peace, people suffer a lot and they are forced to leave their homes and seek refuge in other areas. The poverty the proverb also reflects is the horrible and gloomy picture of the situation in which people find themselves when conflicts occur. This state 
of affairs explains Hausa people's harshness towards and hate of conflict and whoever wants to disturb peace among them. Also, mai son tada hankali (trouble maker) has no respect and consideration in society; that is why individuals make all efforts to control themselves even when they are provoked. This proverb serves as a means of discouraging troubles and encouraging peace in the Hausa society.

Tashin hankali yana kawo tsiya (conflict brings poverty) is, so to speak, used to enhance peaceful coexistence among people. It is considered as a preventive and a curative means of resolving conflicts in society. People use it in their daily exchanges to prevent tensions among themselves. That is why old people like grand-parents initiate children in the importance of preventing disputes by showing them that whoever quarrels will be punished. Moreover, this proverb is used to cure disputes; i.e. to settle conflicts between two persons or groups of persons in the Hausa society. Also, the use of this proverb reveals the Hausa people's perspective of reducing conflicts and maintaining peace. The fifth proverb emphasises above all prevention:

\section{Rigakafi yafi magani}

\section{Prevention is Better than Cure}

Hausa people use this proverb to show the importance of being cautious and vigilant in life. This is the general and global significance of the proverb. They alsouse it to refer to various situations such as health, politics, security, planning, and management. Here, the proverb is used to draw the attention of individuals to being visionaries in order to take advantage of a given situation. In the Hausa society, planning and anticipating are a cardinal principle and they are highly recommended to avoid failure or unwanted results. That is why this proverb is commonly used among people not only to remind them the above-mentioned principle, but also to help them conduct their activities very well.

Furthermore, the proverb rigakafi yafi magani (prevention is better than cure) also means that it is always better to do one's best to preserve peace than to start a conflict. Similarly, M. A. Mode (2015, p. 56) advocates that "According to this proverb it is always better to avoid [a] conflict than allow it to start." Through this quote, Mode shows that the very proverb in question is used to prevent conflicts and promote peace in the Hausa society by suggesting the best way to encourage peaceful coexistence among people. Thus, according to Hausa people rigakafi (prevention) is always the simplest and the most efficient method to set harmony and stability in society. That is why the proverb, in its formation contains a comparison of superiority between rigakafi(prevention) and magani (cure). The Hausa people consider that prevention is not to be compared with cure; this is because of three main reasons: (1) when a conflict starts no one can know how it is going to end; (2) when it starts no one can imagine its consequences; and (3) peace recovery is difficult after a conflict. Therefore, according to the Hausa people's philosophy, individuals must play a great role in peace promotion and conflict prevention. That is why proverbs like rigakafi yafi magani are regularly used among adults and children to achieve this aim. Also, the philosophy relies on a collective awareness to encourage peaceful coexistence by preventing conflicts in society.

\section{CONCLuSion}

Proverbs significantly contribute to the maintenance and promotion of peace in the Hausa society. They are actively used to achieve this objective. This study has unravelled the prominent role proverbs play in ensuring peaceful coexistence and conflict prevention and management among Hausa people. In this perspective, M. Shehu \& I.A. Muhammad (2019, p. 128) observe that "They [Hausa people] employed proverb[s] as a major vehicle in examining causes of conflict, prevention and resolution." Proverbs are therefore a suitable traditional answer to the general instability the world is living today. They are a panacea to the recurrent conflicts and guardian of peace in society.

This Hausa folkloric value (proverbs) reveals the richness and efficacy of African cultural values for a sustainable development. Hausa proverbs can then be used as an African perspective to resolve conflicts throughout the world. As it has been shown through this work, to prevent conflicts and promote peace, proverbs are used at three different levels of peoples' coexistence: 1 . before conflicts as armour and awakener, 2. in conflict periods as stabilizer and conciliator, and 3. after conflict moments as unifier. Furthermore, the research has proven that language is a necessary tool at the disposal of the society to enhance good relationships between individuals and consolidate peace and unity among people. In this perspective, language and society are indissociable. 


\section{REFERENCES}

[1] Abrahams, R. D. (1973).Folklore and Folklife: An Introduction. UK: University of Chicago Press.

[2] Bichi, A. Y. (1995).“Hausa Folk Genres” in Rufa'i et al (eds.) Harsunan Nijeriya, (Vol. Xvii). Centre for the Study of Nigerian Languages, Kano: Bayero University, pp. 150-156.

[3] Finnegan, R.(1970).Oral Literature in Africa. Oxford: Clarendon Press.

[4] Hassan, S.(2009). "Nazarin Karin Magana Da SukeNuna Rarrashi in Harshe 3".In Journal of African Languages, Department of Nigerian and African Languages, Zaria: Ahmad Bello University, pp. 64-77.

[5] Ibrahim, M. S. (1985). "Gudummawar Adabin BakaWajen Raya Al'adu Na Hausa, Littafi Na Uku”, in Rufa'i et al (eds.) Harsunan Nijeriya, (Vol. Xvii). Centre for the Study of Nigerian Languages, Kano: Bayero University, pp. 229-237.

[6] Kabir, U. A.(2005). “The Co-Wife in Hausa Proverbs”. In Dundaye Journal of Hausa Studies.Vol. 1, № 2 , Department of Nigerian Languages, Usman Danfodio University Sokoto, pp. 118-127.

[7] Kirk-Green, A. H. M. (1966).Hausa Ba Dabo Ba Ne: A Collection of 500 Proverbs Translated and Annotated, Ibadan: Oxford University Press.

[8] Madauchi, I. et al. (1980).Hausa Customs. Zaria: the Northern Nigerian Publishing Company Ltd.

[9] Mieder, W.(2004).Proverbs: A Handbook. Greenwood Folklore Handbooks, Greenwood Press.

[10] Mode, M. A.(2015). "Proverbs as Panacea to Peaceful Coexistence in Northern Nigeria". In Journal of Humanities and Social Sciences, Vol. 20, Issue 9, pp. 55-60.

[11] Okpewho, I.(983).Myth in Africa. London, Cambridge University Press.

[12] Sarbi, S. A.(2019). "Hausa Proverbs as a Tool for Discipline". In GbengaIbileye,

[13] et al. (Eds) Gender, Folklore and Cultural Dialectics in African Literature: A Festschrift for Asabe KabirUsman, Makurdi, Sevhage, pp. 133-148.

[14] Shehu, M. \&Muhammad, I. A.(2019). "Roles of Hausa Proverbs in Peace Keeping and Conflict Resolution". In International Journal of Multidisciplinary Research and Development, Vol. 6, Issue 4, pp. $125-128$

[15] Trudgill, P.(2000). Sociolinguistics: An Introduction to Language and Society. Fourth Edition. London: Penguin Books.

[16] Tudunwada, Y. Y. (2006). Hausa A Dunqule, Na Daya, Kano Printing Press.

[17] Wardhaugh, R.(2006).An Introduction to Sociolinguistics. Fifth Edition. Oxford: Basil Blackwell.

[18] Zeinab,A. \&Halima,A.(2015). “Thematic Analysis of Some Selected Hausa Proverbs". InArts and Design Studies, Vol. 27, pp. 27-30.

\section{AUTHORS' BIOGRAPHY}

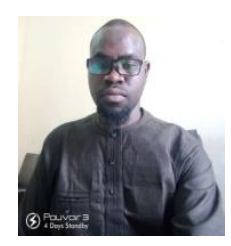

Dr Lawali Maman Toukour, lecturer at the English Department of Université de Zinder, Niger Republic. Specialized in African Oral Literature (Hausa Oral Poetry and Folklore)

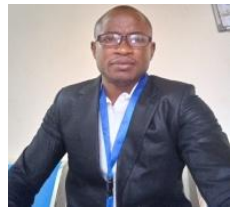

Ayodele Adebayo Allagbé, earned a Doctorate degree in Applied Linguistics in Université d'Abomey-Calavi, in 2015. His areas of interest include but are not limited to Systemic Functional Linguistics, Stylistics, Sociolinguistics, Language Education, Critical Discourse Analysis, Literary Criticism, etc.

Citation: Maman Toukour LAWALI, Ayodele Adebayo ALLAGBE. "Peace Promotion Through Hausa Proverbs: A Sociolinguistic Perspective” International Journal on Studies in English Language and Literature (IJSELL), vol 9, no. 8, 2021, pp. 29-35. doi: https://doi.org/10.20431/2347-3134.0908004.

Copyright: (c) 2021 Authors. This is an open-access article distributed under the terms of the Creative Commons Attribution License, which permits unrestricted use, distribution, and reproduction in any medium, provided the original author and source are credited. 